\title{
ICT Use and Its Influence in Family Functioning With Reference to Process and Structure of Families: A Structural Equation Analysis
}

\author{
Dinesh Kumar J., Anna University, Chennai, India \\ Arulchelvan Sriram, Anna University, Chennai, India
}

\begin{abstract}
ICT use in family functioning is an important area to study as the impact changes when technology grows over years. This research analyzed the role of ICT use in process and structure of families using the factors present in Hertlein multitheoretical model. The additional factor 'family communication pattern' was introduced and tested along with the process factor to know its importance. The study has taken 756 samples (both parents and children) in Chennai and tested two hypothesis. Structural equation model (SEM) was used to analyze the data. The result shows that ICT has influenced the process changes of the families. The structural changes in families are slowly started occurring and that is not as significant as process changes. The added new factor has loaded positively with existing factors, which shows that family communication is important for family process and thus contributed to theoretical development.
\end{abstract}

\section{KEYWORDS}

Family functioning, Family process, Family structure, ICT and family, Hertlein's model

\section{INTRODUCTION}

Family is the fundamental unit of society where a group of people that live together in a permanent arrangement (Cheal, 2002) and it is an important source of security, love, belonging, and identity (Lalor et al., 2007). Various factors affect the functioning of the family. Among that, ICT is at a faster pace. Initially, technology was used for entertainment in families. Nowadays the purpose of the use is slowly changing and it plays a role in all activities of family members. Adults in a family-like to communicate more in messenger and social networking applications using computers and smartphones with their family members, peers, relatives, etc. (Huisman, 2012). For working mothers, the Internet/ chats help to plan their daily activities and engage more time with family members from any place (Moore, 2006). This shows working parents have an option to take most of their office works home and ICT provides more time to spend with family members. Television delivers better educational content for children (Wartella, Richert, \& Robb, 2010), and the use of video games, videos entertain them than engaging in physical activities. ICT applications also help to communicate/facilitate face-to-face interaction with the non-resident family members (Rudi, 2015). ICT is also reflected in 
parenting styles. At times, parents prefer to use ICT related activities such as showing cartoons, videos, and programs to kids through TV or smartphones as a babysitter. In this way, ICT has an association in structure and routine activities of the family such as communication, relationship development, education for children, work-home life balance, leisure activities, parenting styles, and many more.

Many studies done by various authors (which are dealt with in this paper's introduction and literature section) across the world have found the role of ICT use in the family. Those studies are majorly concentrated on developed countries where the technology is well equipped in-household system. Also, the rate of perception and acceptance of technology is different in such countries. Many previous studies also concentrated on studying one ICT among the specific family roles such as father, mother, children, and grandparents. Also, the association of various family functioning variables is not completely focused. Researches in this field are country-specific and it is not suitable to generalize the results to other parts of the world as the family practices changes based on geographical location, culture, provision of technological developments, and nature of acceptance. Hence, there is a need to study how ICT influences the structure and routine activities of families.

This research considered certain of the above-mentioned points as research and the methodological gap in this area. Further, this research studied the influence of ICT usage in the functioning of the family. In studying ICT usage, all the ICT devices which have the possibility of use in family setup was considered without any restrictions. Also, the data was collected from intergeneration family members to extend the scope of the study and understand ICT use in the family across generations.

This study will be a major contribution to the ICT and Family studies area where the Indian region doesn't expose to these kinds of studies more. The technological growth in the country is still in a developing stage. So these kinds of studies will help the country to understand the usage pattern of people to have betterment in many ways to regulate their family life better. In general, this study will be a major support in understanding the influence of ICT in family functioning in both process and structure of the family.

\section{LITERATURE BACKGROUND}

\section{ICT and Family}

Contemporary families are now adapted to various technologies and that became a key for social interaction among family members. Its impact in society is large and sometimes it brings the generational and digital divide that led to the change in family dynamics (McGrath, 2012). McDonald (2015) said that whenever new technology arrives at the home, the process of integration transforms in multiple ways. Television has become more personalized in the home today. Mobile phone, internet, email services are mostly preferred for communication and they are associated with a positive influence of the family as it helps to keep them updated and spend more time together (Kennedy \& Wellman, 2007). Transparency, increased level of communication, adaptability, and cohesion are few positive impacts identified. It also helps parents to engage their children in their interest (Lanigan, 2009). Stevenson (2011) studied the role of ICT use in everyday activities said that the initial entry of ICT at the home is for educational purposes and then it collides with other dimensions of social life. ICT usage in families looks negotiated, supported, and subverted at various times. The multitasking feature of ICT helps make life easier but there is also conflict exists between family members. Stress and other health issues, safety, privacy, access to pornographic contents, less social communication, missing family dining habits, fewer family gatherings, and change in food habits are the problems reported in contemporary family structure due to ICT use (Huisman, 2012). In many families, ICT is used as a baby sitter and that produces negative outcomes in the later period in family dynamics (Villegas, 2013). Parent-children conflict arises when children are frustrated about their parent's lack of knowledge related to ICT use. Digital Inequalities, familial tension, information communication illiterate are more common in the digital home when the members belong to a different generation (Clark, 2009). 
Ghazanfar et al., (2015) said that ICT can alter the family institution, family developmental stages, and brought a cultural change.

\section{ICT AND FAMILY FUNCTIONING}

The literature related to the ICT and family functioning grows over the years along with the technology. Carvalho et al., (2017) found that ICT association helps for a better, healthy, and positive family functioning. Except for the isolation and addiction problems reported commonly among children in the family, more positive measures were identified to organize the family life better. Romero-Ruiz et al., (2017) found distanced communication, video calls, social networks, sharing of images and videos, amusement, entertainment, banking, and shopping online are positives of ICT. Lack of family talks, relationship destruction, high virtual communication, reduction of family time, less physical interaction, distance making, solitude, lacking affection, family disunity, replacing emotions are considered negatives of ICT use.

Whenever a new technology is introduced into the family, it alters and brings in new roles or proficiency alongside the prevailing ones and that leads to relational changes (Mesch, 2006; Wait \& White, 1999). In that case, families are categorized by the order of authority concerning its members. Kiesler et al., (2000) said that when the family roles are redefined and a new member emerges as head, new dynamics are introduced into the families. Mesch (2006 a) found that adolescent's expertise in technical aspects is the main indicator of intergenerational conflicts in the family and that leads to the reversal of family roles between parents and children.

Couples in ICT enriched families perceive that many times their partner behave in hurtful ways and creates conflict due to new ICT rules (Daneback, Cooper, \& Mansson, 2005). Concerning parents and children, cross verification of contents, monitoring software, and revisiting the children visited sites become the frequent activity of parents in an ICT home and that made the parents encompass new rules to their children. Wang et al., (2005) found that $61 \%$ of parents restrict the internet use of their children. They set rules for children based on their own experience and technical knowledge. Parents with more technical knowledge are dominant and confident in imposing family rules than others.

Mesch $(2006,2006 \mathrm{~b})$ studied the role of ICT in family boundaries found that more internet usage served for games, social participation is positively associated with conflicts. The time spent with family members and conflicts is linked with internet use and family cohesion. "Always on" facility of technology positively associated with the family connectedness but negative in the family boundary. The development of relationship using technology with outside family members pose a greater risk, threat, and give unpleasant online experience (Williams, 2011; Pratt, 2012). Also, the invasion of academic and professional work towards home has redefined the family boundaries (Wajcman et al., 2008). Few times, the ease of information flow from inside and outside the family is easy through internet use and that also helps to expand the family boundaries.

Regarding the role of intimacy, it is frequently seen among the sibling/other family members groups who engage in more online social functions (McMillan \& Morrison, 2006). Brady et al., (2015) studied the ICT use and process changes of Hertlein's multitheoretical model and found that "tech-savvy" families are more intimate with their family members. He also found that various types of device or ICT based services accessed are the predictor for relationship maintenance and family intimacy. Bacigalupe \& Lambe (2011) said that the virtual presence of ICT helps to strengthen family intimacy with non-resident family members. Wajcman et al., (2008) said that mobile phone helps for micro coordination and reduce the fear and utilized for deeper contact with family members. ICT provides an inexpensive and user-friendly communication environment (Bacigalupe \& Lambe, 2011; Wilding, 2006) that helps to maintain an enriched relationship with the family members.

Hertlein (2012) has researched the influence of ICT in family functioning variables by analyzing the role of technology in couple and family relationships. In that research, he proposed a model based on the integration of three theories and proved the association of ICT use in structure and process 


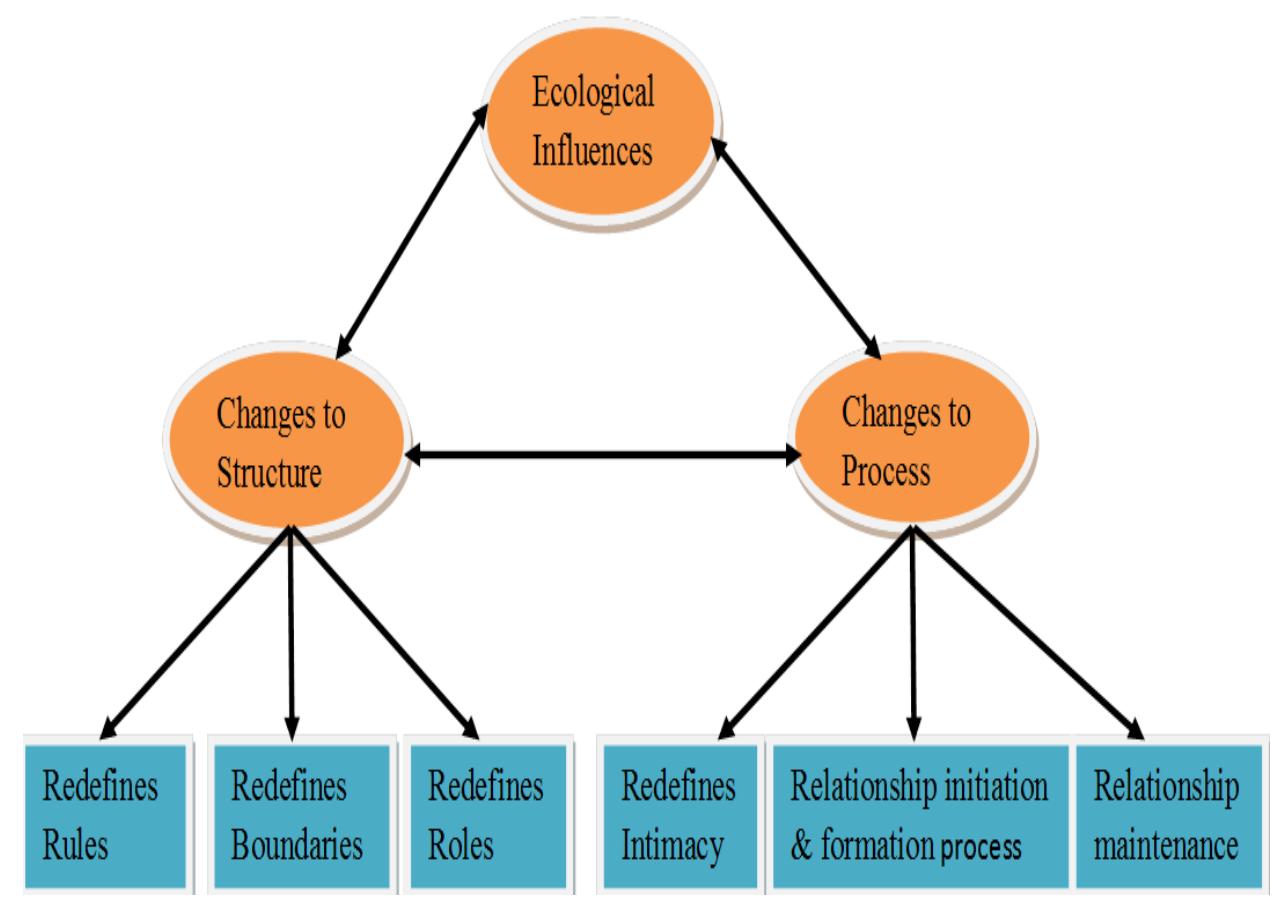

changes of family functioning. The author has also dealt with various sub-factors for family functioning variables and found the association between them.

Based on the previous works, it is understood that the role of ICT usage in family functioning and family members are present. Family functioning variables suggested by Hertlein (2012) was adopted for this study. In ecological influences of ICT, this research has taken only the accessibility factor and proposed to test it with structural and process changes of the family.

\section{Theoretical Model}

The conceptual model for this paper was adopted from Hertlein's (2012) multi-theoretical model which links the family functioning variables with technology. The model was created by integrating three theories such as family ecology perspective, structural-functional perspective, and interactionconstructionist perspective theories. Family ecology perspective related to how environment variable affects families. A structural-functional perspective talks about how families organized to meet their needs concerning rules, roles, and boundaries. The interaction constructionist perspective talks about how family members initiate and develop relationships with each other.

The illustration of the model has three main associated factors of ICT and family (see Figure 1). They are ecological influences of ICT, changes to the structure, and changes to the process. Ecological influence is categorized as accessibility, anonymity, affordability, acceptability, approximation, ambiguity, accommodation. Structural changes include a redefinition of family rules, family boundaries, and family roles. Process changes include a redefinition of family intimacy, family relationship initiation and formation, and family relationship maintenance.

In addition to the variables present in the model, many other families, and technology researchers concentrate on the communication perspective which is the key element of the family process. Smith et al., (2009) and McGrath (2012) said that family communication is an important aspect of the family process and a key to effective family functioning. Thulin, (2005) pointed out that social communication 


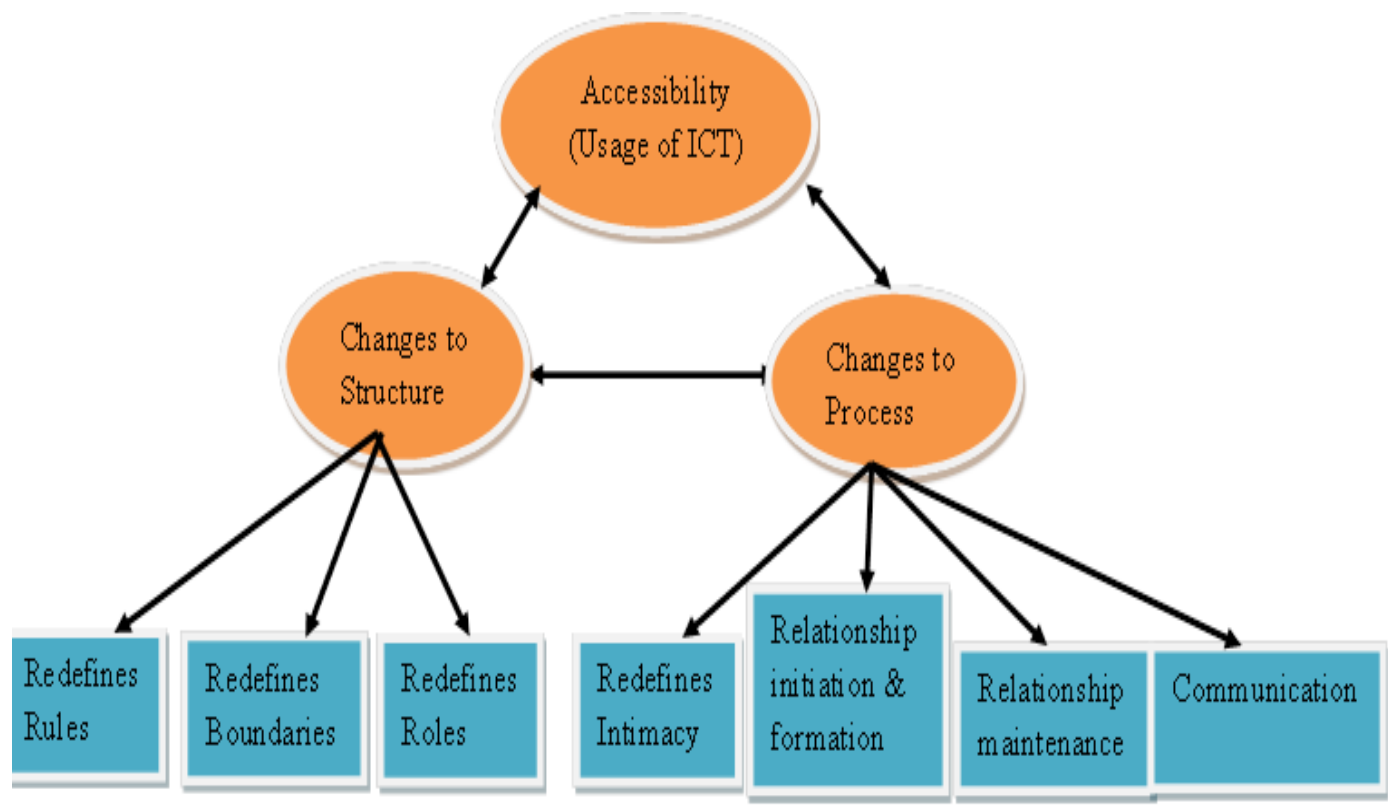

becomes possible in the ICT environment and that helps to connect with the family members and friends. Mesch (2006) pointed out that work from home is possible using ICT devices. Lanigan (2009) found that cellphones help to coordinate the everyday activities of family members and that made them feel secure and safe. Chesley and Fox (2012) reported the positive family communication in an ICT environment among women as it also told the reinforcement and stable maintenance of bonds with family members.

Short et al. (1976) and Sproull \& Kiesler (1986) said that ICT shift the interaction of family members towards technology and create an unhealthy environment, misunderstanding, antisocial behavior, relationship hurdles among the people. Haythornthwaite (2005) said that moving away from the face to face interaction and depending only on ICT creates weaker ties and less social communication in the family. DiMaggio et al., (2001) said that the higher the ICT usage lesser the communication between family members. They discussed literature on the importance of communication and ICT signifies both positive and negative effects. Having strong evidence, this research added family communication as an additional factor in the process changes, and the extended conceptual model is created (see Figure 2).

\section{Hypothesis}

Based on the literature review and theoretical model, the following research hypothesis is framed.

Hypothesis One: ICT use influence the structural functioning of the families Hypothesis Two: ICT use influence the process functioning of the families

\section{DEVELOPMENT OF MEASUREMENT ITEMS}

Before testing the research hypothesis, a part of this research was done to develop the measurement items of Hertlein's multitheoretical model. The measurement items were developed through literature analysis and focus group discussion. After the thorough literature study, the tentative statements 
and questionnaire were prepared for focus group discussion. The discussion was conducted with 10 experts from different fields related to the research study such as family members, family counselors, psychologists, media practitioners, and academicians. When considering family members, all generation members were given importance to understand the opinion of all types of family members. The experts participated in the discussion and gave opinion regarding the ICT influence according to their field they are working about family life. In the focus group, five major areas were concentrated for discussion such as the role of ICT in the family, challenges faced by family members due to ICT, the role of ICT in various factors present in Hertlein's multi-theoretical model, influencing factors of ICT in family functioning, and the influence of ICT in family communication. The discussion was recorded by the researcher and the tentative statements for each factor were created. After the discussions, the final statements are created and that was submitted to two expert members and one family member to verify the credibility, similarity, subjective, and language errors. The reason for the incorporation of a family member in item assessment is to ensure that all the important points are added from the family member's point of view and academic experts were used for the subjective assessment of the questionnaire. Totally 46 statements are created for all eight factors and that was statistically verified using exploratory and confirmatory factor analysis. After the analysis 5 statements are dropped from the analysis and 41 items are considered as final. This research was carried out with those 41 items (Refer to Table 7 in Appendix A) to test the hypothesis.

\section{Reliability and Validity of Measurement Items}

The reliability and validity of the questionnaire are explained below.

\section{Reliability}

Reliability is the assessment of the degree of consistency/measure of internal consistency between multiple measurements of variables. It helps to understand that the items denoted under the factors are highly correlated with their factor than the other factor (Hair et al., 2013) and ensure that the responses taken at a different period don't vary to a large extent and it's reliable. To measure the questionnaire reliability, Cronbach's alpha value was considered in this research. 0.60 to 1 is considered as an accepted range and the value closer to 1 indicates higher reliability and less error (Hair et al., 2013). The questionnaire items the different factors were achieved a reliability value range from 0.699 to 0.898 in this study. To mention in detail, the family communication pattern factor achieved the highest reliability (0.898) followed by Family Intimacy (0.847), ICT Usage (0.818), Family Relationship Maintenance (0.793), Family Boundaries (0.783), Family Rules (0.746), Family Roles (0.710) and Family Relationship initiation and Formation (0.699). The Cronbach's alpha values are in the required range. Hence the questionnaire items under the factors are considered reliable.

\section{Validity}

Validity is used to understand whether the items in the scale have measured the same thing that it is intended to measure (Zikmund et al., 2003). To measure the internal validity of the items, this research reported content, convergent, and discriminant validity as per the previous author's review (Hair et al., 2013).

Content Validity is the subjective assessment of measurement items that must be carried out through an expert's analysis. In this research, the items were analyzed and finalized based on the 10 expert members during the focus group discussion and 2 experts post-focus group discussion. They help in building the measurement items involving the scientific procedure. Since the content validity is a subjective assessment and doesn't have numerical value to prove and enough expert advice was got, it is considered that the face validity is proved.

Convergent validity is the measure of highly correlated variables within a single factor. This is analyzed by looking at the factor loading values. Above 0.5 for each item is considered accepted. In 
this research, among the total 41 measurement items, the standardized factor loading values ranges from 0.568 to 0.871 were achieved. Since this is a sufficient number, the convergent validity is proved.

Discriminant validity refers to the extent to which the factors are not related to other factors. In such a case, items should correlate with their factor higher than the other factors and the cross-loading must not be present. In this research, the factors correlated strongly with its factor than others. Also, the items which cross-loaded were removed during the initial screening process. So, no cross-loading values were present among the factors. Hence discriminant validity is proved.

\section{SAMPLING AND DATA COLLECTION METHODS}

This research has adopted a survey method using a self-reported questionnaire as a tool for data collection. Chennai city in Tamil Nadu was selected as a sample city to collect data. Chennai is considered one of the major cosmopolitan cities in India that contains the heterogeneous nature of the population from all districts of the state. The city has more than 9 million populations and is categorized into 3 divisions such as north, south, and central. The three divisions are further classified into 15 zones and 200 wards. The samples from the city were selected based on the multi-stage sampling method. The multistage sampling method is generally used for choosing samples when the size of the population is large. This method provides a great deal of flexibility in the category, number, and size of samples in each stage. It also provides the opportunity for classification/stratification at various stages of the design in the population (Ezzati-Rice \& Murphy, 1995). Three or more stages are commonly used and each stage follows some sampling method such as Simple Random Sampling (SRS), systematic sampling, cluster, stratified, etc. for selecting the samples. After the deduction of a large population into smaller categories in each stage, the sample size was finally derived (Chauvet, 2015).

This research follows six stages to derive the final samples. In stage one, all three divisions were considered for the study. In stage two, six zones ( 2 from each division of a total of 15) were selected using the SRS technique. In stage three, five wards are selected using SRS from each of the six selected zones. In stage four, five streets from each 30 selected wards are selected using the SRS technique. So, a total of 150 streets were selected. In stage five, three families were selected from the chosen 150 streets. Hence, a total of 450 families were taken for this study. In stage 6, the family members were divided into two different strata such as Parent and Child. One member from each stratum was selected randomly. If any of the members from a particular stratum is not available, then the particular family is dropped from the survey, and another family is selected in that particular street using the same SRS technique.

Among the 450 families, only 378 are considered for the analysis process. 72 families are removed during the data purification process because the researcher has identified missing values of more than $50 \%$ in those survey forms. Finally, 756 members from 378 families are considered for data analysis.

\section{ANALYTICAL PROCEDURE}

The results are analyzed using Structural Equation Modelling (SEM) analysis. Generally, the SEM method results are reported in two phases. They are (i) Measurement model and (ii) Structural model. In this paper results of both the phases are analyzed under the categories such as model summary, parameter estimation, and model fit indices. In the measurement model, the validation measures are reported additionally. The analysis was done using IBM AMOS software. 
Table 1. Demographic details of the survey respondents

\begin{tabular}{|c|c|c|c|}
\hline Demographic Variables & Category & Frequency & Percentage (\%) \\
\hline \multirow[t]{5}{*}{ Age Group (in years) } & $8-15$ & 37 & 5 \\
\hline & $16-25$ & 259 & 34 \\
\hline & $26-35$ & 91 & 12 \\
\hline & $36-55$ & 268 & 36 \\
\hline & $56-75$ & 101 & 13 \\
\hline \multirow[t]{2}{*}{ Gender } & Male & 360 & 48 \\
\hline & Female & 396 & 52 \\
\hline \multirow[t]{3}{*}{ Educational Qualification } & Schooling & 232 & 31 \\
\hline & UG & 358 & 47 \\
\hline & PG & 166 & 22 \\
\hline \multirow[t]{4}{*}{ Marital Status } & Single & 322 & 42.6 \\
\hline & Married & 408 & 54 \\
\hline & Widow & 24 & 3.2 \\
\hline & Divorced & 2 & 0.3 \\
\hline \multirow[t]{6}{*}{ Occupation } & Student & 258 & 34 \\
\hline & Government & 90 & 12 \\
\hline & Private & 206 & 27 \\
\hline & Business & 80 & 11 \\
\hline & Home Maker & 106 & 14 \\
\hline & Retired & 16 & 2 \\
\hline \multirow[t]{4}{*}{ Family Roles } & Father & 182 & 24 \\
\hline & Mother & 196 & 26 \\
\hline & Son & 178 & 24 \\
\hline & Daughter & 200 & 26 \\
\hline
\end{tabular}

\section{RESULTS}

\section{Demographic Profile of the Respondents}

The demographic details of the survey respondents are presented in (Table 1). The data shows that the 16-25 and 36-55 age group contribute 70\% of the samples in the study. The least age group participants are from 8-15 groups. The gender distribution of samples is closer to an equal proportion. Educationwise $69 \%$ of the samples are either UG or PG qualified and $31 \%$ belong to school education. Half of the samples are married and the other half are single. Only a few percentages belong to the widow or divorce category. The reason for more singles is due to the inclusion of children samples in the study. Among the family roles, it is found that $24 \%$ of the respondents belong to father and $26 \%$ is a mother. In the same way, $24 \%$ is a son and $26 \%$ are a daughter. 
Figure 3. Measurement model correlating all factors

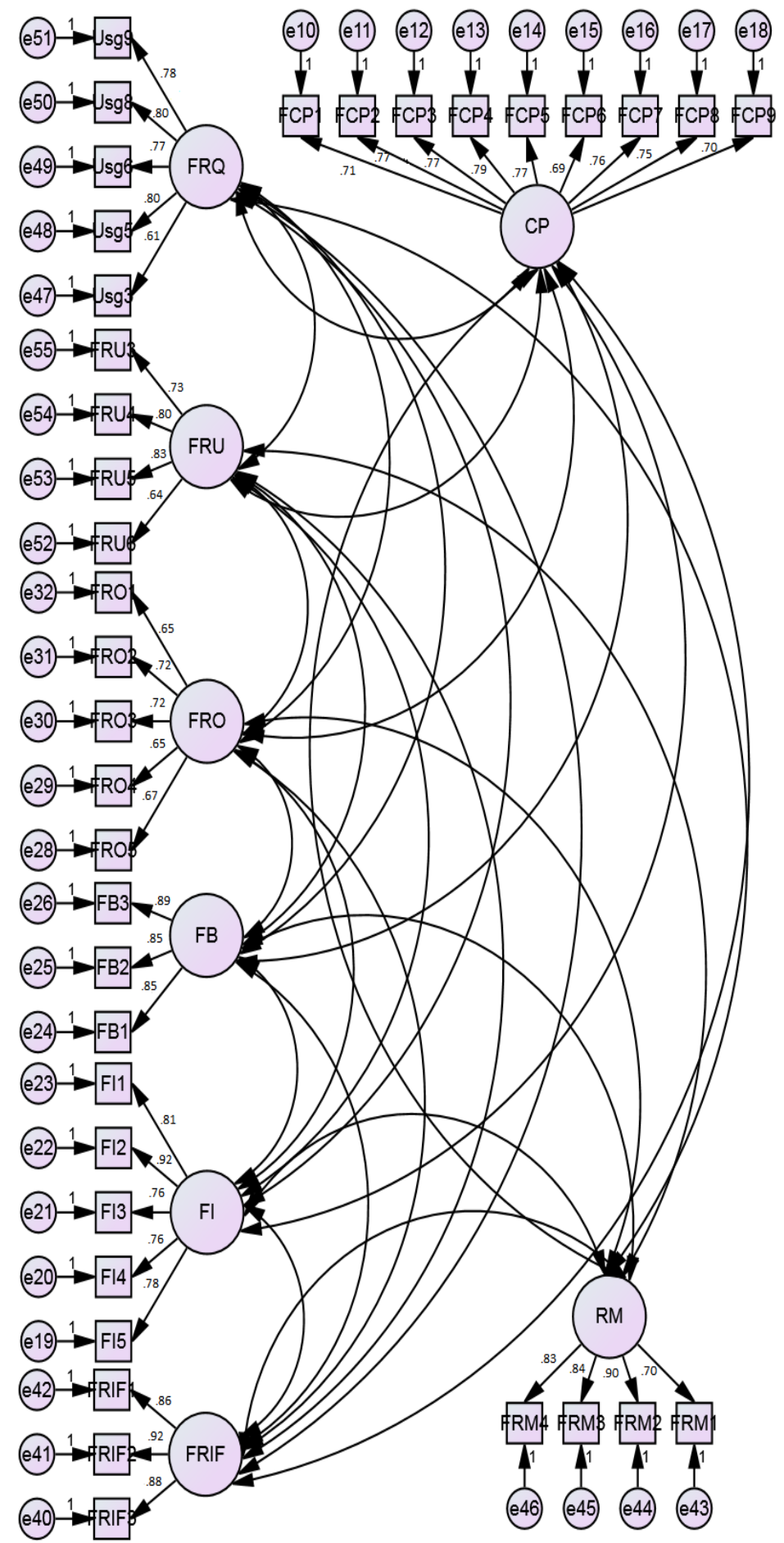


Table 2. Path Estimates, Critical Ratio, AVE \& CR of the measurement model

\begin{tabular}{|c|c|c|c|c|c|c|c|}
\hline \multicolumn{3}{|l|}{ Path } & \multirow{2}{*}{$\begin{array}{l}\text { Standardized } \\
\text { Path Estimate } \\
.709\end{array}$} & \multirow{2}{*}{$\begin{array}{l}\text { C.R. } \\
\text { (T Value) }\end{array}$} & \multirow{2}{*}{$\begin{array}{l}\text { P } \\
\text { (Significance) }\end{array}$} & \multirow{2}{*}{$\begin{array}{l}\text { Average } \\
\text { Variance } \\
\text { Extracted } \\
\text { (AVE) }\end{array}$} & \multirow{2}{*}{$\begin{array}{l}\text { Construct } \\
\text { Reliability } \\
\text { (CR) }\end{array}$} \\
\hline FCP1 & $<---$ & $\mathrm{FCP}$ & & & & & \\
\hline FCP2 & $<---$ & $\mathrm{FCP}$ & .767 & 20.512 & $* * *$ & & \\
\hline FCP3 & $<---$ & FCP & .767 & 16.197 & $* * *$ & & \\
\hline FCP4 & $<---$ & $\mathrm{FCP}$ & .791 & 16.838 & $* * *$ & & \\
\hline FCP5 & $<---$ & $\mathrm{FCP}$ & .766 & 16.041 & $* * *$ & & \\
\hline FCP6 & $<---$ & $\mathrm{FCP}$ & .688 & 14.086 & $* * *$ & & \\
\hline FCP7 & $<---$ & $\mathrm{FCP}$ & .759 & 14.321 & $* * *$ & & \\
\hline FCP8 & $<---$ & $\mathrm{FCP}$ & .751 & 13.837 & $* * *$ & & \\
\hline FCP9 & $<---$ & FCP & .696 & 13.558 & $* * *$ & & \\
\hline FI5 & $<---$ & FI & .776 & & & 0.653 & 0.904 \\
\hline FI4 & $<---$ & FI & .761 & 14.669 & $* * *$ & & \\
\hline FI3 & $<--$ & FI & .763 & 14.594 & $* * *$ & & \\
\hline FI2 & $<---$ & FI & .915 & 16.430 & $* * *$ & & \\
\hline FI1 & $<--$ & FI & .810 & 15.375 & $* * *$ & & \\
\hline FB1 & $<---$ & FB & .890 & & & 0.754 & 0.902 \\
\hline FB2 & $<---$ & FB & .848 & 19.471 & $* * *$ & & \\
\hline FB3 & $<---$ & FB & .850 & 19.530 & $* * *$ & & \\
\hline FRO5 & $<---$ & FRO & .665 & & & 0.466 & 0.813 \\
\hline FRO4 & $<---$ & FRO & .653 & 3.247 & .001 & & \\
\hline FRO3 & $<---$ & FRO & .722 & 3.806 & $* * *$ & & \\
\hline FRO2 & $<---$ & FRO & .722 & 3.650 & $* * *$ & & \\
\hline FRO1 & $<---$ & FRO & .646 & 7.408 & $* * *$ & & \\
\hline FRIF3 & $<--$ & FRIF & .881 & & & 0.787 & 0.917 \\
\hline FRIF2 & $<---$ & FRIF & .917 & 22.851 & $* * *$ & & \\
\hline FRIF1 & $<---$ & FRIF & .856 & 6.596 & $* * *$ & & \\
\hline FRM1 & $<---$ & FRM & .829 & & & 0.674 & 0.891 \\
\hline FRM2 & $<--$ & FRM & .836 & 16.154 & $* * *$ & & \\
\hline FRM3 & $<--$ & FRM & .895 & 14.955 & $* * *$ & & \\
\hline FRM4 & $<--$ & FRM & .695 & 8.352 & $* * *$ & & \\
\hline Usg3 & $<--$ & FRQ & .606 & & & 0.571 & 0.868 \\
\hline Usg5 & $<--$ & FRQ & .804 & 11.029 & $* * *$ & & \\
\hline Usg6 & $<--$ & FRQ & .769 & 11.804 & $* * *$ & & \\
\hline Usg8 & $<---$ & FRQ & .804 & 10.547 & $* * *$ & & \\
\hline Usg9 & $<---$ & FRQ & .778 & 10.969 & $* * *$ & & \\
\hline FRU6 & $<---$ & FRU & .641 & & & 0.568 & 0.839 \\
\hline FRU5 & $<--$ & FRU & .834 & 11.745 & $* * *$ & & \\
\hline FRU4 & $<---$ & FRU & .796 & 11.614 & $* * *$ & & \\
\hline FRU3 & $<--$ & FRU & .730 & 10.532 & $* * *$ & & \\
\hline
\end{tabular}




\section{RESULTS OF THE MEASUREMENT MODEL}

\section{Measurement Model Summary}

The measurement model was measured by correlating all the factors present in Hertlein's theoretical model along with the extension of family communication pattern factor in process changes (Figure 3 ). Totally 8 factors and 84 variables present in the model including 38 observed and 46 unobserved variables. ICT usage factor has 5 measurement items, Family rules have 4 measurement items, Family roles has 5 measurement items, Family boundaries has 3 measurement items, Family intimacy has 5 measurement items, Family relationship initiation and formation has 3 items, Family relationship maintenance has 4 items and Family communication pattern has 9 measurement items. Among the initial 41 measurement items, 3 items (one item each from usage, family rules, and family boundaries factor) are deleted during confirmatory analysis due to poor loading. So, a total of 46 exogenous and 38 endogenous variables present in the model. In this measurement model, 104 parameters/ relationships are estimated thus leaving 637 degrees of freedom. This provides the over-identified model yielding the chi-square value of 963.655 and probability level.000.

\section{Measurement Model Parameter Estimation}

Parameter estimation was explained by reporting the values of standardized path estimates, critical ratio (CR) value, and significance value presented in (Table 2). The ideal value of 0.7 and above in standardized parameter estimates is considered as good. It is found that except for a few items all other measured items attained greater than 0.7 . When using new scales 0.6 is considered as a satisfying range (Hair et al., 2014) and following that standardized estimation is attained in this model for all the measurement items. Next, the Critical Ratio (CR) values of all the items are above \pm 1.96 at a $1 \%$ level of significance which is required. Hence the model estimation parameters attained the satisfied values and we move into the other section to assess model fit.

\section{Measurement Model Fit Indices}

The purpose of measuring the Goodness of Fit (GOF) indices is to check whether the estimated values are similar to the observed values. If the observed values of the model are closer to the estimated values, then the theoretical development made in the research is considered perfect. In the SEM model, there are different GOF indices available.

Chi-square is considered as the basic measure to understand the difference between observed and estimated values. Low chi-square and the non-significant $\mathrm{p}$-value are required to prove this step because a closer association is expected between the observed and estimated value. But chi-square value generally calculated related to the sample size and the chance of getting low chi-square and the non-significant $\mathrm{P}$-value is not always possible. So the alternate fit indices need to be measured. Normed Chi-square (CMIN/DF) is one of the alternate measures. It is the measure of a simple ratio of the chi-square to the degrees of freedom. A value of less than 3 is considered an excellent model fit. This model has got the value 1.644 which is considered as very less than the required value. So the initial estimation of model fit is achieved.

Apart from normed chi-square, the other absolute (GFI, RMSEA, RMR, SRMR), incremental (NFI, TLI, CFI), and parsimony fit measures (AGFI, PNFI) are checked to denote more credibility and accuracy to the model. Absolute fit indices are a direct measure that specifies how the observed data was reproduced properly to fit the model. Goodness-of-fit index (GFI) is the measure to produce a fit value that is not much sensitive to the sample size. Root Mean Square Error of Approximation (RMSEA) is the fit measure that helps to correct the tendency of chi-square value which rejects the model with larger indicators or samples. It corrects the model complexity and sample size by using it in the computation. Root Mean Square Residual (RMR) is the square root of the mean of squared residuals. The standardized RMR (SRMR) which represents the average standardized residual is useful to comparing fit in the models. 
Table 3. Model fit indices of the Measurement model

\begin{tabular}{|c|c|c|}
\hline The goodness of fit (GOF) index & Estimated Model Value & References \\
\hline Chi-Square $\left(\chi^{2}\right)$ & 963.655 & \multirow{18}{*}{$\begin{array}{l}\text { Bentler, 1992; Hu \& Bentler, 1999; } \\
\text { Schreiber et al., 2006; Hair et al., } \\
\text { 2014; Byrne, } 2016\end{array}$} \\
\hline Probability Value & .000 & \\
\hline Degrees of Freedom (DOF) & 637 & \\
\hline \multicolumn{2}{|l|}{ Absolute Fit Measures } & \\
\hline GFI & .938 & \\
\hline PGFI & .742 & \\
\hline RMSEA & $.029(.026$ to .032$)$ & \\
\hline RMR & .049 & \\
\hline SRMR & .0402 & \\
\hline Normed Chi-Square & 1.644 & \\
\hline \multicolumn{2}{|l|}{ Incremental Fit Measures } & \\
\hline NFI & .920 & \\
\hline TLI & .960 & \\
\hline CFI & .967 & \\
\hline \multicolumn{2}{|l|}{ RNI } & \\
\hline \multicolumn{2}{|l|}{ Parsimony Fit Measure } & \\
\hline AGFI & .921 & \\
\hline PNFI & .767 & \\
\hline
\end{tabular}

Incremental fit indices assess how the estimated model fits the baseline model (i.e. null model). The null model assumes all observed variables are uncorrelated. This fit index helps to improve the fit of the model by the specification of multi-item constructs related. Normed Fit Index (NFI) is the incremental fit indices that denote the ratio of the difference in chi-square value for the fitted model and the null model divided chi-square value for the null model. Tucker-Lewis Index (TLI) is similar to NFI. It is the comparison of the normed chi-square values for the null and specified model. The comparative fit index (CFI) is the normed version of NFI.

Table 4. Discriminant Validity of the measurement model

\begin{tabular}{|l|l|l|l|l|l|l|l|l|}
\hline & FB & FI & FRQ & FRO & FRU & FRIF & RM & FCP \\
\hline FB & $\mathbf{0 . 8 6 8}$ & & & & & & & \\
\hline FI & -0.058 & $\mathbf{0 . 8 0 8}$ & & & & & & \\
\hline FRQ & -0.052 & 0.099 & $\mathbf{0 . 7 5 5}$ & & & & & \\
\hline FRO & 0.179 & -0.014 & 0.054 & $\mathbf{0 . 6 8 3}$ & & & & \\
\hline FRU & 0.046 & 0.258 & 0.045 & 0.023 & $\mathbf{0 . 7 5 4}$ & & & \\
\hline FRIF & -0.038 & 0.405 & 0.080 & 0.009 & 0.072 & $\mathbf{0 . 8 8 7}$ & & \\
\hline FRM & -0.028 & 0.333 & 0.097 & 0.047 & 0.041 & 0.707 & $\mathbf{0 . 8 2 1}$ & \\
\hline FCP & 0.067 & 0.494 & 0.179 & 0.060 & 0.202 & 0.239 & 0.171 & $\mathbf{0 . 7 4 6}$ \\
\hline
\end{tabular}




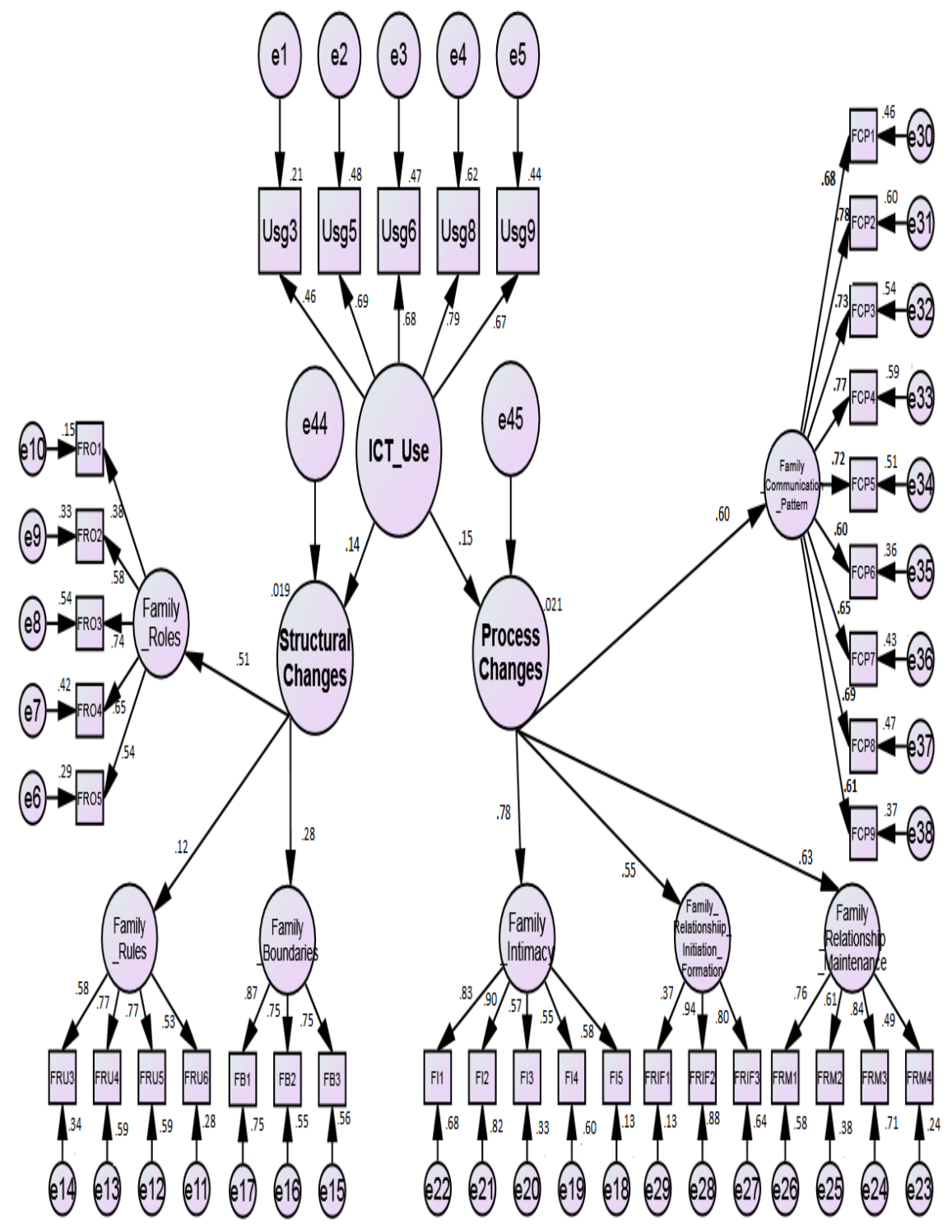

Parsimony fit indices provide information regarding which model is considered as best considering its fit to complexity. It is calculated as the ratio of degrees of freedom (DOF) used by a model to the total degrees of freedom (DOF) available. It is similar to the adjusted R-square value that is related to the model fit. Adjusted Goodness of Fit Index (AGFI) is calculated by adjusting the GFI by a ratio of the degrees of freedom used in the model to total degrees of freedom available. It helps to reduce the complexity of the model and helps to estimate with a minimum number of free paths. Parsimony Normed Fit Index (PNFI) adjusts the NFI by multiplying it times the PF. This value helps to compare one model to another being the highest PNFI is most supported.

Analyzing the model fit indices presented in (Table 3), GFI (0.938), NFI (0.920), TLI (0.960), CFI (0.967), and AGFI (0.921) provide a well-fit model value. The value of RMSEA in this model is .029 with a $90 \%$ confidence interval ranging from .026 and .032 . It is further interpreted that $90 \%$ 
Table 5. Path Estimates, CR value, P-value and Result of the structural model

\begin{tabular}{|l|l|l|l|l|l|l|l|l|}
\hline Hypothesis & \multicolumn{2}{|l|}{ Path } & $\begin{array}{l}\text { Standardized } \\
\text { Path- } \\
\text { Coefficient }\end{array}$ & S. E & $\begin{array}{l}\text { C.R. (T } \\
\text { Value) }\end{array}$ & P-Value & Result \\
\hline H1 & Structure & $<--$ & Usage & .139 & .040 & 1.680 & .093 & Not Supported \\
\hline H2 & Process & $<--$ & Usage & .146 & .038 & 3.164 & $.002 * *$ & Supported \\
\hline $\begin{array}{l}\text { Note: ** denotes at significant at 1\% level } \\
* \text { denotes at significant at 5\% level }\end{array}$
\end{tabular}

confident that the RMSEA value in the sample/population falls within the range of .026 to .032. Since the required value of below .05 is achieved, it is considered an excellent fit. RMR and SRMR values are .049 and .0402 indicate the better fit as the value closer to zero indicates a better fit. Overall, the model has attained the required value and found to be an excellent fit.

\section{Measurement Model Validity Measures}

In the measurement model, convergent and discriminant validity are the central measures to report. Convergent validity measures the variables that are highly correlated within a single factor. It is measured through factor loadings, average variance extracted (AVE), and construct reliability (CR). The Average Variance Extracted (AVE) is the variance of mean extracted for the loading of the particular item present in the construct. Construct Reliability is the measures of convergent validity which is computed from the squared sum of factor loadings for each construct and sum of the error variance of the construct. AVE ranges above 0.5 and CR above 0.6 is considered as a valid range of measures. All AVE values are above 0.5 except for family roles. The AVE for family roles is closer to 0.5 . So the value is considered as accepted. The construct reliability for all the factors is above 0.6 . Hence convergent validity measures are reported successfully.

Measuring discriminant validity is done by analyzing the correlation estimates between the constructs. In correlation, the estimate of variance extracted should be greater than the squared correlation present in the diagonal presented in (Table 4). The values in the diagonal are greater than the other correlation present between the factors. Hence discriminant validity is proved.

\section{RESULTS OF STRUCTURAL MODEL}

\section{Model Summary}

The structural model was drawn based on the connections provided in Hertlein's Multi-theoretical model. The model follows the second order illustration approach in which there are three main constructs and seven sub-constructs (Figure 4). Structure factor contains family rules, family roles, and family boundaries as its sub construct and process factor contain family intimacy, family relationship initiation and formation, family relationship maintenance, and family communication pattern as its subconstructs. The measurement items related to the sub-constructs are linked appropriately. Overall, the model has one independent (ICT usage) and two dependent variables (structure and process changes). The minimum of the structural model was achieved with 741 distinctive sample moments. Based on the overall connection it is estimated that 48 exogenous and 47 endogenous variables present by estimating 81 parameters with 660 degrees of freedom. The structural model is also identified as an overidentified model with a chi-square value of 1001.669 and a significant p-value of .000 is achieved. 
Table 6. Model fit indices of the structural model

\begin{tabular}{|c|c|c|}
\hline The goodness of fit (GOF) index & Estimated Model Value & References \\
\hline Chi-Square $\left(\chi^{2}\right)$ & 1001.669 & \multirow{17}{*}{$\begin{array}{l}\text { Bentler, 1992; Hu \& Bentler, 1999; } \\
\text { Schreiber et al., 2006; Hair et al., } \\
\text { 2014; Byrne, } 2016\end{array}$} \\
\hline Probability Value & .000 & \\
\hline Degrees of Freedom (DOF) & 660 & \\
\hline \multicolumn{2}{|l|}{ Absolute Fit Measures } & \\
\hline GFI & .937 & \\
\hline RMSEA & $.030(.026$ to .033$)$ & \\
\hline RMR & .052 & \\
\hline SRMR & .0427 & \\
\hline Normed Chi-Square & 1.658 & \\
\hline \multicolumn{2}{|l|}{ Incremental Fit Measures } & \\
\hline NFI & .917 & \\
\hline TLI & .959 & \\
\hline CFI & .965 & \\
\hline \multicolumn{2}{|l|}{$\mathrm{RNI}$} & \\
\hline \multicolumn{2}{|l|}{ Parsimony Fit Measure } & \\
\hline AGFI & .922 & \\
\hline PNFI & .788 & \\
\hline
\end{tabular}

\section{Parameter Estimation of Structural Model}

The parameter estimation of the structural model was reported using the standardized path estimates, standard error, critical ratio, significance value, and the result of the hypothesis is presented in (Table $5)$.

Analyzing the standardized path coefficient between the ICT usage and structural changes it is found that 0.139 is the estimated value. The critical ratio (CR) value which needs to be above 1.96 is estimated at 1.680 in the model. The significant p-value is 0.093 which is not significant. Based on this estimation it is concluded that ICT usage doesn't influence the structural changes in the family. Hence hypothesis 1 is not supported.

Looking at the path estimate value between ICT usage and process changes it is found that the standardized estimate is 0.146 with a CR value of 3.164 and p-value (0.002) significant at a $1 \%$ level. This significant estimation of $\mathrm{p}$-value and $\mathrm{CR}$ value shows that there is an influence present between the process changes of family and ICT usage. Hence hypothesis 2 is supported. Hence it is concluded that ICT usage has influenced the process of the family functioning and not the family structure.

The results also analyzed the validity of the second order constructs with first-order constructs to understand the credibility of the relationship between the main constructs and sub-constructs. In structural changes, the path estimation between structure and family roles is 0.51 , structure and family rules are 0.12 , and structure and family boundaries are 0.28 . The weak relationship estimates for family rules and family boundaries show that no standard connection exists between those variables and family roles have more influence than the other two factors.

In process changes, the path estimation between process and family intimacy (0.78), family relationship initiation and formation (0.55), family relationship maintenance $(0.63)$, and family communication pattern (0.60) are found to be satisfied and significant. Among that, family intimacy plays a major influential/contributory role in process changes of the family followed by 
family relationship maintenance, family communication pattern, and family relationship initiation and formation. Especially the newly added sub-construct family communication pattern loaded significantly with the process changes factor indicates the extension of the Hertlein Multi-theoretical model is meaningful and the contribution of family communication pattern plays a vital role in process changes of the family members.

\section{Model Fit Measures of the Structural Model}

The extension of Hertlein's multi-theoretical model which intended to study the influence of ICT usage in family functioning in this research has got a high chi-square value and significant p-value. As denoted already in the measurement model results, the alternated normed chi-square was analyzed to avoid a higher sample size issue in reporting chi-square and found that 1.658 of normed chi-square is less than 3 provides the consideration of best fit model.

Reporting absolute fit measures in (Table 6), such as GFI (0.937), incremental fit measures such as NFI (0.917), TLI (0.959), CFI (0.965), and parsimony fit measures such as AGFI (0.922) has attained the desired value i.e. $>0.90$ and the model fit indices is estimated successfully. RMSEA value of 0.030 at $90 \%$ confidence interval ranging from 0.026 and 0.033 is less than the expected value of below 0.07. RMR (0.052) and SRMR (0.0427) values are also found to be adequate than the expected range. These fit indices indicate the better fit of the extension of Hertlein's Multi-theoretical structural model.

\section{DISCUSSION}

The result of the study indicates the association of ICT usage in the functioning of the family. Hypothesis 1 which deals with the link between ICT use and structural changes is not supported. This indicates the ICT use has not made a considerable reflection on changing the structure of the family. It is also to note that not all the variables (family roles, rules, and boundaries) formed the structural changes factor in the model has higher loading. Among the three, only family roles sub-factor loaded above 0.5 which indicates that the role of family members frequently changes due to ICT use has partially influenced the family dynamics (Mesch, 2006; Kiesler et al., 2000). Since many researchers (Daneback, Cooper, \& Mansson, 2005; Mesch, 2006; Wang et al., 2005) specify the implications/ change of family rules in the ICT environment, this research has found negative results. Also, low loading for family boundaries indicates the changes that occurred to ICT has not much contributed to the structural changes.

Hypothesis 2 which deals with the association between the ICT and process changes shows the existence of influence between variables. Previous studies were done by Bacigalupe \& Lambe (2011), Wajcman et al., (2008), and Brady et al., (2015) specified the importance and change ICT brings in the intimacy factor and that was also supported in this research with high loading (0.78). This shows that the family intimacy sub-factor has influenced to a greater extent than other associated variables of the family process. Family relationship maintenance is the next higher loading subfactor (0.63) which dealt with process changes. Consistent with previous study results (Kennedy and Wellman, 2007; Brady et al., 2015; Chesley and Fox, 2012), this research also proves that relationship maintenance is influenced by the use of ICT. Another sub-factor 'family communication' added in the model under process changes has become the third-highest influencing factor (0.60). The reason many authors (Smith et al., 2009; McGrath, 2012; Thulin, 2005; Lanigan, 2009; Short et al., 1976; Haythornthwaite, 2005; Villegas, 2013; Rudi et al., 2015; Devitt and Roker, 2009) supported the important role of communication in process changes of families was once again proved in this research. The higher validation of the communication factor also indicates the need for including that as a separate variable in family functioning models. Compared to the other three sub-factors, relationship initiation and formation have loaded with low value (0.55) indicates it as the least influencing in the family process. This shows that even though ICT use has brought a changing scenario in intimacy, 
relationship maintenance, and communication, forming relationships in the ICT environment is still challenging and family members are more conscious about it.

Comparing hypotheses one and two, it is clear that hypothesis two (process changes) was influenced by the ICT use, and the same is also supported by Brady et al., (2015). Though hypothesis one is not supported, the validation of the model proved with required values and thus it can be considered for further theoretical development in this field.

\section{CONCLUSION}

This research has analyzed and identified the existence of process changes in families due to ICT use. The structural changes values reported to an extent show that it is slowly occurring and those opinions create a conflict between family members. The same research also added and successfully integrated the 'family communication pattern' factor in the model with the required values. This shows the importance of communication in the family process more strongly. Overall the validation of the model proved the hypothesis with a good fit.

\section{LIMITATIONS AND FUTURE DIRECTIONS}

This research has limited to Chennai city in Tamil Nadu, India. Extending the same to other parts of India may yield a result related to diversified culture and family practices in India. This research focused on cosmopolitan city family functioning practices. Comparing the same with rural and urban structure will give different and interesting results. Also, the research can be carried out between the two countries.

This research has used only one variable ('Accessibility' factor) in the environmental variables of Hertlein's model. In the future, the research can include other variables and test its validation of the model. This research has used one methodology (Survey) and cross-sectional. Future research may include a qualitative method to collect more subjective data in-depth and long term evaluation studies may be considered. This longitudinal study helps to understand the ICT influence in the family across different family stages, life cycles, etc.

\section{RECOMMENDATIONS}

The study recommends a few suggestions (theoretically \& practically) to the family members, communication experts, technology developers, researchers, and psychologists. To family members, the suggestion is to implement rules for ICT use in the family. Psychologists when handling family problems or related issues should also consider the technology influence in families and address the concerns to the family members. They must speak about the importance of family relationships, benefits/effective use of ICT use, ways to build positive family systems, health hazards of ICT use. Academicians should highlight the importance of family values and the proper use of technology to students. Communication experts and scholars can do varied research in this area based on long term observation, family cycle, types of ICT, types of family members, etc. Media must highlight the consequences of technology use in the family by doing campaigns, advertisements, drama-based programs, live interaction with family members, etc. The analysis and comparison of various family and technology models yield new outputs. Technology developers can add a time frame/alarm based notification to monitor or restrict the overuse of devices. 


\section{REFERENCES}

Bacigalupe, G., \& Lambe, S. (2011). Virtualizing intimacy: Information communication technologies and transnational families in therapy. Family Process, 50(1), 12-26. doi:10.1111/j.1545-5300.2010.01343.x PMID:21361921

Bentler, P. M. (1992). On the fit of models to covariances and methodology to the Bulletin. Psychological Bulletin, 112(3), 400-404. doi:10.1037/0033-2909.112.3.400 PMID:1438635

Bentler, P. M., \& Yuan, K. H. (1999). Structural equation modeling with small samples: Test statistics. Multivariate Behavioral Research, 34(2), 181-197. doi:10.1207/S15327906Mb340203 PMID:26753935

Brady, J. T., Lee, B., \& Rha, J. Y. (2015). An exploration of families' use of information and communication technology: The case of Korea and the United States. International Journal of Human Ecology, 16(2), 79-88. doi:10.6115/ijhe.2015.16.2.79

Byrne, B. M. (2016). Structural Equation Modeling with Amos: Basic Concepts, Applications, and programming. Routledge. doi:10.4324/9781315757421

Carvalho, J., Fonseca, G., Francisco, R., Bacigalupe, G., \& Relvas, A. P. (2016). Information and Communication Technologies and Family: Patterns of Use, Life Cycle, and Family Dynamics. Journal of Psychology \& Psychotherapy, 6(1), 1-3. doi:10.4172/2161-0487.1000240

Carvalho, J., Francisco, R., \& Relvas, A. P. (2017). ICTs and Family Functioning: A Study on Portuguese Families with Adolescents and Emerging Adults. Contemporary Family Therapy, 39(4), 281-288. doi:10.1007/ s10591-017-9436-8

Chauvet, G. (2015). Coupling Methods for Multistage Sampling. Annals of Statistics, 43(6), 2484-2506. doi: $10.1214 / 15-A O S 1348$

Cheal, D. J. (2002). Sociology of Family Life. Palgrave. doi:10.1007/978-1-137-04826-4

Chesley, N., \& Fox, B. (2012). E-mail's use and perceived effect on family relationship quality: Variations by gender and race/ethnicity. Sociological Focus, 45(1), 63-84. doi:10.1080/00380237.2012.630906

Clark, L. S. (2009). Digital Media and Generation gap: Qualitative research on US teens and their parents. Information Communication and Society, 12(3), 388-407. doi:10.1080/13691180902823845

Daneback, K., Cooper, A., \& Mansson, S. A. (2005). An Internet study of cybersex participants. Archives of Sexual Behavior, 34(3), 321-328. doi:10.1007/s10508-005-3120-z PMID:15971014

Devitt, K., \& Roker, D. (2009). The role of mobile phones in family communication. Children \& Society, 23(3), 189-202. doi:10.1111/j.1099-0860.2008.00166.x

DiMaggio, P., Hargittai, E., Neuman, W. R., \& Robinson, J. P. (2001). Social Implications of the Internet. Annual Review of Sociology, 27(1), 307-336. doi:10.1146/annurev.soc.27.1.307

Ezzati-Rice, T. M., \& Murphy, R. S. (1995). Issues Associated with the Design of a National Probability Sample for Human Exposure Assessment. Environmental Health Perspectives, 103(3), 55-59. PMID:7635113

Ghazanfar, S., Zeeshan, M., Kifayat, U., Shehnaz, S., \& Hussain, M. (2015). Changes in family values due to information communication technologies. Explorer, 1(10), 385-389.

Hair, J., Black, W., Babin, B., \& Anderson, R. (2014). Exploratory factor analysis. Multivariate data analysis (7th ed.). Harlow, UK: Pearson Education.

Haythornthwaite, C. (2005). Social networks and Internet connectivity effects. Information Communication and Society, 8(2), 125-147. doi:10.1080/13691180500146185

Hertlein, K. M. (2012). Digital dwelling: Technology in couple and family relationships. Family Relations, 61(3), 374-387. doi:10.1111/j.1741-3729.2012.00702.x

Huisman, S., Edwards, A., \& Catapano, S. (2012). The impact of technology on families. International Journal of Education and Psychology in the Community, 2(1), 44-62. 
Kennedy, T. L., \& Wellman, B. (2007). The Networked Household. Information Communication and Society, 10(5), 645-670. doi:10.1080/13691180701658012

Kiesler, S., Zdaniuk, B., Lundmark, V., \& Kraut, R. (2000). Troubles with the internet: The dynamics of help at home. Human-Computer Interaction, 15(4), 323-351. doi:10.1207/S15327051HCI1504_2

Lalor, K., Róiste, A., \& Devlin, M. (2007). Young People in Contemporary Ireland. Gill \& Macmillan.

Lanigan, J. D. (2009). A socio-technological model for family research and intervention: How information and communication technologies affect family life. Marriage \& Family Review, 45(6-8), 587-609. doi:10.1080/01494920903224194

McDonald, T. (2015). Affecting relations: Domesticating the internet in a south-western Chinese town. Information Communication and Society, 18(1), 17-31. doi:10.1080/1369118X.2014.924981

McGrath, S. (2012). The impact of New Media Technologies on Social Interaction in the Household (Undergraduate Dissertation). Retrieved from https://www.maynoothuniversity.ie/sites/default/files/assets/ document/SiobhanMcGrath.pdf

McMillan, S. J., \& Morrison, M. (2006). Coming of age with the Internet: A qualitative exploration of how the Internet has become an integral part of young people's lives. New Media \& Society, 8(1), 73-95. doi: $10.1177 / 1461444806059871$

Mesch, G. S. (2006a). Family characteristics and intergenerational conflicts over the internet. Information Communication and Society, 9(4), 473-495. doi:10.1080/13691180600858705

Mesch, G. S. (2006b). Family relations and the internet: Exploring a family boundaries approach. Journal of Family Communication, 6(2), 119-138. doi:10.1207/s15327698jfc0602_2

Moore, A. M. (2006). A Parent's look at technology. Montessori Life, 18(2), 11.

Pratt, V. (2012). Adaptations to Technology and its Effect on Communication and Cohesion in the Family Context. Poster presented at the Undergraduate Research Conference (URC) at Stephen F. Austin State University. Retrieved from https://scholarworks.sfasu.edu/cgi/viewcontent.cgi?article=1012\&context=urc

Romero-Ruiz, K., Echeverri-Sánchez, L., Peña-Plata, J., Vásquez-Giraldo, S., Aguilera-Cardona, M., HerazoAvendaño, C., \& Bran-Piedrahita, L. (2017). Information and communication technologies impact on family relationship. Global Journal of Health Science, 9(6).

Rudi, J., Dworkin, J., Walker, S., \& Doty, J. (2015). Parents use of Information and communication technologies for family communication: Differences by age of children. Information Communication and Society, 18(1), 78-93. doi:10.1080/1369118X.2014.934390

Schreiber, J. B., Nora, A., Stage, F. K., Barlow, E. A., \& King, J. (2006). Reporting structural equation modeling and confirmatory factor analysis results: A review. The Journal of Educational Research, 99(6), 323-338. doi:10.3200/JOER.99.6.323-338

Short, J., Williams, E., \& Christie, B. (1976). The Social Psychology of Telecommunications. John Wiley \& Sons.

Smith, K. M., Freeman, P. A., \& Zabriskie, R. B. (2009). An Examination of Family Communication within the Core and Balance Model of Family Leisure Functioning. Family Relations, 58(1), 79-90. doi:10.1111/j.17413729.2008.00536.x

Sproull, L., \& Kiesler, S. (1986). Reducing social context cues: Electronic mail in organizational computing. Management Science, 32(11), 1492-1512. doi:10.1287/mnsc.32.11.1492

Stevenson, O. (2011). From public policy to family practices: Researching the everyday realities of families' technology use at home. Journal of Computer Assisted Learning, 27(4), 336-346. doi:10.1111/j.13652729.2011.00430.x

Thulin, E., \& Vilhelmson, B. (2005). Virtual mobility of urban youth: ICT based communication in Sweden. Journal of Economic and Social Geography, 96(5), 477-487. doi:10.1111/j.1467-9663.2005.00480.x

Villegas, A. (2013). The Influence of Technology on Family Dynamics. In Proceedings of the New York State Communication Association. Fordham University. 
Wait, D., \& White, J. M. (1999). Computers and family life: A family development perspective. Journal of Comparative Family Studies, 30(1), 1-15. doi:10.3138/jcfs.30.1.1

Wajcman, J., Bittman, M., \& Brown, J. E. (2008). Families without borders: Mobile phones, connectedness, and work-home divisions. Sociology, 42(4), 635-652. doi:10.1177/0038038508091620

Wang, R., Bianchi, S. M., \& Raley, S. B. (2005). Teenagers' Internet use and family rules: A research note. Journal of Marriage and Family, 67(5), 1249-1258. doi:10.1111/j.1741-3737.2005.00214.x

Wartella, E., Richert, R. A., \& Robb, M. B. (2010). Babies, television, and videos: How did we get here? Developmental Review, 30(2), 116-127. doi:10.1016/j.dr.2010.03.008

Wilding, R. (2006). Virtual intimacies? Families communication across transnational contexts. Global Networks, 6(2), 125-142. doi:10.1111/j.1471-0374.2006.00137.x

Williams, A. L., \& Merten, M. J. (2011). iFamily: Internet and social media technology in the family context. Family and Consumer Sciences Research Journal, 40(2), 150-170. doi:10.1111/j.1552-3934.2011.02101.x 


\section{APPENDIX $A$. LIST OF STATEMENTS USED IN THE SURVEY}

\section{Table 7. Measurement items used in the survey}

\begin{tabular}{|c|c|c|}
\hline Factors & Codes & Scaling Items \\
\hline \multirow[t]{6}{*}{ ICT Usage } & Usg3 & How often you text your family members? \\
\hline & Usg5 & How often you use email services to send information to family members? \\
\hline & Usg6 & How often you connect with your family members through social networking websites or applications? \\
\hline & Usg7 & How often you play video games at home? \\
\hline & Usg8 & How often you access the internet at home? \\
\hline & Usg9 & How often you avail of e-services through ICT devices for your home needs? \\
\hline \multirow[t]{5}{*}{ Family Rules } & FRU3 & My family restricts the ICT usage and the younger people shouldn't question the older/head of the family member. \\
\hline & FRU4 & My family members allow me to talk about only important issues through ICT to ensure safety. \\
\hline & FRU5 & My family members sometimes feel different if they have other views regarding access to ICT \\
\hline & FRU6 & When I am at home, I am expected to follow the rules of my family members regarding ICT use. \\
\hline & FRU7 & Socializing through ICT devices is questionable in my family \\
\hline \multirow[t]{5}{*}{ Family Roles } & FRO1 & I can operate all the ICT devices in my home without other's help. \\
\hline & FRO2 & I myself learn the usage of new ICTs in my home. \\
\hline & FRO3 & $\begin{array}{l}\text { I listen to my other family member who is technologically strong while taking decisions related to that despite the age } \\
\text { difference. }\end{array}$ \\
\hline & FRO4 & In our family young adults (myself) play a major role in using technology. \\
\hline & FRO5 & ICT has redefined the hierarchy of family members roles in my family \\
\hline \multirow[t]{4}{*}{ Family Boundaries } & FB1 & I discuss the private information regarding my family issues in the ICT forum \\
\hline & FB2 & $\begin{array}{l}\text { The wide range of possibilities through ICT devices provides inappropriate information that sometimes affects the functions } \\
\text { of my family. }\end{array}$ \\
\hline & FB3 & I prefer to develop new relationships online using SNS such as Facebook, Twitter, or through any other ICT devices. \\
\hline & FB4 & ICT has a role in changing family boundaries \\
\hline \multirow[t]{5}{*}{ Family Intimacy } & FI1 & ICT helps to develop a long-lasting relationship with my family members \\
\hline & FI2 & ICT facilitates closer bonding with my family members \\
\hline & FI3 & ICT helps to communicate certain things effectively if it cannot be conveyed face to face irrespective of age \\
\hline & FI4 & Virtual communication helps to engage in frequent interaction with the family members \\
\hline & FI5 & ICT helps to stay emotionally connected with my family members \\
\hline \multirow[t]{3}{*}{ Family Relationship initiation and formation } & FRIF1 & ICT helps to find new relationships and I prefer it \\
\hline & FRIF2 & ICT helps to develop a relationship with my family members \\
\hline & FRIF3 & ICT helps to construct a strong relationship among my family members. \\
\hline \multirow[t]{4}{*}{ Family Relationship maintenance } & FRM1 & ICT provides the opportunity to keep in touch with my family members all the time \\
\hline & FRM2 & Frequent communication with family members is possible through ICT devices. (Ex: instant message, voice call, video call, etc.) \\
\hline & FRM3 & ICT helps to strengthen the ties with family members \\
\hline & FRM4 & $\begin{array}{l}\text { ICT provides the inexpensive and user-friendly communication environment to interact with transnational family members/ } \\
\text { missing contacts (Ex: family members who are abroad or separated) }\end{array}$ \\
\hline \multirow[t]{9}{*}{ Family Communication Pattern } & FCP1 & I usually tell my family members what I am thinking about different things immediately and effectively using ICT devices \\
\hline & FCP2 & I could tell my family members almost everything through ICT \\
\hline & FCP3 & I prefer to share my feelings and emotions with the family members through ICT frequently. \\
\hline & FCP4 & I often have a long conversation with my family members on any topic in an ICT environment/using ICT devices. \\
\hline & FCP5 & My family members always ask my opinions during the conversation through ICT devices. \\
\hline & FCP6 & $\begin{array}{l}\text { My family members encourage me to express my feelings about academic/work-related issues more while using ICT than direct } \\
\text { conversation }\end{array}$ \\
\hline & FCP7 & My family members tend to be very open about their emotions only during the conversations with ICT \\
\hline & FCP8 & I and my family members used to have frequent interactions regarding the daily works using ICT \\
\hline & FCP9 & I often talk with my family members about plans and hopes for the future using ICT than direct conversation. \\
\hline
\end{tabular}


Dr. J Dinesh Kumar is the Teaching Fellow in the Department of Media Sciences, Anna University, Chennai, Tamil Nadu, India. He completed his Master's Degree in Electronic Media and worked in Regional Television Channel in the News Department before the academic entry. He has completed his Ph.D. in the area of ICT and Family. He has published several articles, chapter in books in the international journals/books and attended many international and national conferences. His area of teaching interest includes Journalism, Script writing, media production and user experience design. He has also worked with his research supervisor in many research projects related to child rights, child marriage, sanitation and health. He also attended many training programs related to media discipline and equipping himself with new innovations

S. Arulchelvan (PhD) is the Associate Professor in the Department of Media Sciences, Anna University, Chennai, India. Earlier, he worked as a Journalist in leading Tamil dailies. He has been awarded FCT Post-Doctoral Research Fellowship from the University of Aveiro, Portugal and The Graciano Lopez Jaena Fellowship in Community Journalism by the University of Philippines. His specializations are Journalism, Development Communication, Educational Media and Community Media. He has been passionately engaged in several research projects with the support of UNICEF, Department of Rural Development, Government of Tamil Nadu and other international and national agencies and he completed around ten major and minor research projects in the area of communication, development and journalism. He has authored few books and has published more than 50 articles in reputed journals that focus on journalism, media and the youth, sanitation and hygiene and other development communication areas. He has also presented papers and participated in various national/ international conferences and visited countries like Thailand, Turkey, Portugal, Germany, Italy, USA, Philippines, Finland and Canada. He had been invited as an expert for several workshops. In addition, He has organized many workshops and seminars on Communication, Journalism, Media and E-Content creation. Moreover, He is in respectable correlation with prominent Indian and foreign professional associations. He has been in the editorial board of many research journals. In addition to teaching, he is also the Curriculum Development Coordinator and has developed and written course material for various subjects like journalism, news writing and development communication among others. He has successfully guided eleven Ph.D., scholars in earning their doctoral degrees and is currently guiding more others. He is serving as a member in Board of Studies in many colleges and universities. 